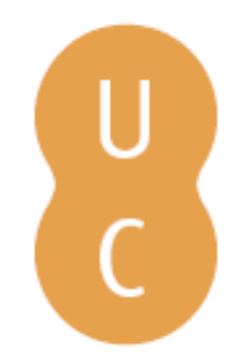

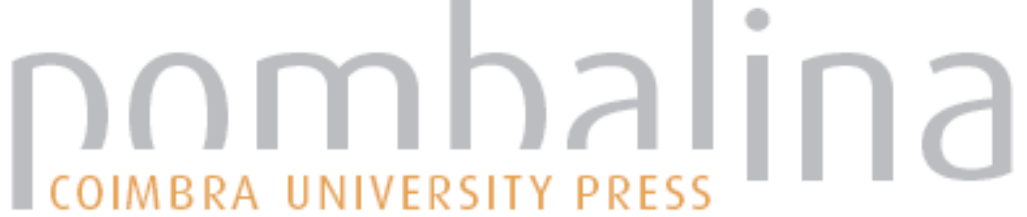

\section{Barita e bentonita: funções no fluido de perfuração e potencial de uso das reservas do nordeste do Brasil}

\author{
Autor(es): $\quad$ Baltar, C. A. M.; Luz, A. B. \\ Publicado por: Imprensa da Universidade de Coimbra \\ URL \\ persistente: URI:http://hdl.handle.net/10316.2/31466 \\ DOI: $\quad$ DOI:http://dx.doi.org/10.14195/978-989-26-0531-9_31 \\ Accessed : $\quad$ 26-Apr-2023 13:42:36
}

A navegação consulta e descarregamento dos títulos inseridos nas Bibliotecas Digitais UC Digitalis, UC Pombalina e UC Impactum, pressupõem a aceitação plena e sem reservas dos Termos e Condições de Uso destas Bibliotecas Digitais, disponíveis em https://digitalis.uc.pt/pt-pt/termos.

Conforme exposto nos referidos Termos e Condições de Uso, o descarregamento de títulos de acesso restrito requer uma licença válida de autorização devendo o utilizador aceder ao(s) documento(s) a partir de um endereço de IP da instituição detentora da supramencionada licença.

Ao utilizador é apenas permitido o descarregamento para uso pessoal, pelo que o emprego do(s) título(s) descarregado(s) para outro fim, designadamente comercial, carece de autorização do respetivo autor ou editor da obra.

Na medida em que todas as obras da UC Digitalis se encontram protegidas pelo Código do Direito de Autor e Direitos Conexos e demais legislação aplicável, toda a cópia, parcial ou total, deste documento, nos casos em que é legalmente admitida, deverá conter ou fazer-se acompanhar por este aviso.

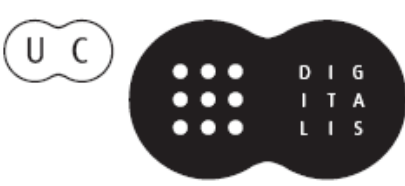





\title{
BARITA E BENTONITA: FUNÇÓES NO FLUIDO DE PERFURAÇÃO E POTENCIAL DE USO DAS RESERVAS DO NORDESTE DO BRASIL
}

\author{
BENTONITE AND BARITE: ROLE IN DRILLING FLUIDS AND \\ POTENTIAL FOR THE USE OF BRAZIL NORTHEASTERN RESERVES
}

\author{
C. A. M. Baltar ${ }^{1} \&$ A. B. Luz ${ }^{2}$
}

\begin{abstract}
Resumo - O sucesso da perfuração de um poço de petróleo, tanto do ponto de vista técnico como do econômico, depende fortemente da composição e propriedades do fluido durante a perfuração. A barita e a bentonita são minerais importantes na formulação de lamas para perfuração de poços de petróleo. A bentonita é usada com as funçôes principais de controlar a viscosidade do fluido e de evitar o retorno dos detritos. Por sua vez a barita atua como agente modificador de densidade do fluido. A região nordeste do Brasil tem uma posição de destaque na produção desses minerais industriais, especialmente, nos estados da Bahia e da Paraíba. A bentonita denominada "verde-lodo" apresenta o maior potencial para uso em lamas de perfuraçáo de poços de petróleo. Enquanto a barita Miguel Calmon, na Bahia, apresenta um elevado teor e uma contaminação à base de quartzo o que facilita bastante o beneficiamento por flotação. Com a descoberta recente dos depósitos do pré-sal e a entrada de empresas privadas para o setor, espera-se que nos próximos anos haja um aumento de investimentos na exploração e produção de petróleo, o que certamente aumentará a demanda por esses insumos minerais.
\end{abstract}

Palavras-chave - fluidos de perfuração; bentonita; barita.

Abstract - The success in oil well drilling, under technical and economical aspects, depends strongly on the control of the composition and properties of the fluid during the drilling. Barite and bentonite are so important minerals components in the oil well drilling fluids. Bentonite is used for the control of the fluid viscosity and to prevent the return of debris. On the other hand, barite is used as a fluid density modifier. The Northeastern Region of Brazil has a prominent position in the industrial minerals production, especially, at Babia

\footnotetext{
${ }^{1}$ Universidade Federal de Pernambuco - Departamento de Engenharia de Minas, Brasil; camb@ufpe.br

${ }^{2}$ CETEM - Centro de Tecnologia Mineral, Brasil; adaobluz@cetem.gov.br
} 
and Paraiba states. The bentonita called "verde-lodo" has the highest potential for use as oil well drilling fluid. In the other side, the barite from Miguel Calmon, Bahia state, presents a high barium sulphate content and quartz contamination which make easier its beneficiation by flotation process. With the recent discovery of the pre-salt deposits and the entry of private companies in this sector, it is expected that in the next years there will be an increased investment in exploration and production of oil, which will certainly increase the demand for these minerals inputs.

Keywords - drilling fluids; bentonite; barite, well drilling

\section{1 - Introduçáo}

A utilização de um fluido ("lama") é essencial na perfuração de um poço. O sucesso da operaçấo depende da composição e das propriedades do fluido que pode exercer diversas funções (DARLEY \& GRAY, 1988):

- Transporte do material cortado pela broca, para a superfície, através do espaço anular do poço;

- Resfriamento e limpeza da broca;

- Redução da fricção entre o colar da coluna de perfuração e as paredes do poço;

- Preservação da estabilidade da seção do poço não revestida;

- Controle da pressão a fim de evitar a entrada de fluxos de óleo, gás ou água proveniente das rochas perfuradas;

- Formação de uma torta (reboco) pouco espessa, de baixa permeabilidade para selar os poros e outras aberturas na formação penetrada pela broca;

- Ajuda na coleta e interpretação de informaçôes disponíveis a partir de amostras de calha, testemunho de sondagem e perfis elétricos;

- Reduçáo do peso da tubulaçáo, devido ao empuxo, de forma a reduzir a tensão no mecanismo de perfuraçẫo.

O fluido de perfuração é bombeado para dentro do poço através da tubulação central. Ao sair, sob pressão, no final da tubulaçáo, o fluido arrasta os detritos de rocha e retorna à superfície pelo espaço anular entre a tubulação e as paredes do poço. O fluido deve circular a uma velocidade maior do que a velocidade de sedimentaçáo das partículas removidas, a fim de que os resíduos possam chegar à superfície (LUZ \& BALTAR, 2003).

\section{2 - Classificação dos fluídos}

Os fluidos de perfuração são classificados com base no componente principal, que pode ser: água, óleo e gás. Quando o principal constituinte é um líquido (água ou óleo), aplica-se o termo lama à suspensão de sólidos no líquido. Neste caso, tem-se uma lama à base de água ou à base de óleo. Quando a água e o óleo estão presentes, forma-se uma emulsão com agitação e a adição de um agente emulsificante. A natureza química do emulsificante determina se o óleo é emulsificado na água (lama de emulsão de óleo, ou 
seja, a água é a fase contínua) ou se a água é emulsificada no óleo (lama de emulsão inversa, ou seja, o óleo é a fase contínua).

Os fluidos também podem ser classificados com relação ao seu conteúdo em sólidos, como de alto e baixo teor de sólidos. Nos fluidos de baixo teor em sólidos, os insumos minerais são parcialmente substituídos por produtos químicos, a exemplo do Carboxilmetilcelulose (CMC) e do amido que têm substituído a bentonita na função de reduzir a perda do fluido por filtração. Os fluidos com baixo teor de sólidos são indicados nos casos de ameaça de desestabilização do poço.

\section{3 - Minerais industriais nos fluidos de perfuração}

Os minerais industriais mais utilizados na indústria do petróleo são: bentonita, barita, atapulgita, sepiolita, vermiculita, magnetita porosa, carbonato de cálcio, mica, perlita expandida, lignina, mica, grafita, cloreto de sódio, gipsita e gilsonita (CASTELLI, 1994), que podem ser usados na forma "in natura" ou após algum beneficiamento.

A perfuração de petróleo é o segmento que usa a maior quantidade de minerais industriais, destacando-se seis funçôes básicas: modificador de densidade; promotor de viscosidade ("viscosifier"); agente anti-espessante ("thinner"); material contra perda de circulação; estabilizadores e lubrificantes.

\section{a) Modificador de densidade}

É necessário que o fluido de perfuração exerça um diferencial de pressão frente às camadas que poderão ser encontradas durante a perfuração, de forma a impedir o influxo, ou seja, que petróleo ou gás jorre do poço (fenômeno conhecido como blowout). Essa pressão, que depende da densidade do fluido, pode ser controlada com a adição de minerais com elevado peso específico.

Minerais como barita, hematita e galena, por apresentarem peso específico elevado (4,5; 5,3 e 7,5, respectivamente) são os mais usados para ajustar a densidade do fluido em função da pressão hidrostática requerida para a coluna de lama. No Brasil é utilizada apenas a barita.

\section{b) Promotor de viscosidade}

O controle da viscosidade é importante nos fluidos de perfuração de poços. O fluido suspende, e transporta até a superfície, os detritos resultantes da ação da broca giratória sobre a rocha. Essa função é exercida com maior eficiência por um fluido viscoso. Por outro lado, a pressão necessária para o bombeamento, e a dificuldade para a remoção dos detritos antes do descarte, aumentam com a viscosidade do fluido.

Os insumos minerais utilizados com essa finalidade possuem propriedades tixotrópicas, o que significa que a viscosidade varia em função da movimentação do fluido. Isso é importante porque, em caso de problemas operacionais ou quando é necessária a troca da broca, a movimentação do fluido é interrompida provocando a formaçáo de um gel espesso que impede o retorno dos fragmentos de rocha evitando a obstruçáo da broca e do poço. No momento em que o movimento é reiniciado, o fluido torna-se mais fino e retorna ao seu estado anterior. 
A bentonita sódica e a bentonita cálcica ativada são os principais minerais utilizados para conferir viscosidade à lama de perfuração à base de água doce. Em água salgada, a bentonita perde as suas propriedades tixotrópicas. Nesse caso, usa-se a atapulgita ou a sepiolita. As argilas organofílicas (bentonitas modificadas com surfatantes) são usadas em lamas à base de óleo para aplicaçóes especiais e lamas de emulsão inversa para perfuração de poços que atravessem formação contendo camadas de folhelho. Para essa função também são usados produtos orgânicos como amido, carboxilmetilcelulose-CMC, tanino e lignosulfonato.

\section{c) Material contra perda de circulação}

$\mathrm{Na}$ primeira fase da perfuração, quando se avança em direção ao reservatório, a formação rochosa deve permanecer impermeável a fim de evitar a infiltração e, conseqüente, perda do fluido de perfuração.

Existe uma variedade muito grande de materiais usados como selantes para prevenir a perda de circulaçáo. A mica é o mineral industrial mais utilizado para reduzir as perdas de circulação. No entanto, outros produtos encontrados no mercado podem ser usados: fibras de celulose picada; celofane picado; conchas de nozes, fibra de celulose classificada; mistura de grãos, entre outros.

Ao contrário, quando o poço alcança o reservatório, deve-se modificar a composição do fluido a fim de garantir o escoamento fácil do petróleo pelos poros da formação até o interior do poço.

\section{d) Estabilizadores}

Nos casos em que o poço atravessa uma camada de sal, o contato do fluido à base de água com a formação tende a provocar a erosão e desestabilização das paredes do poço. Problemas também são previstos na passagem por uma camada formada por material argiloso. A argila hidrata e expande podendo provocar o aprisionamento da ferramenta de perfuração do poço. Para evitar a desestabilização e o alargamento do poço, pela ação da água, adiciona-se ao fluido um agente inibidor.

Minerais como a gipsita ou a gilsonita são utilizados para assegurar a estabilização do poço, dependendo da natureza da formação atravessada pela perfuração. A gipsita (quimicamente, um sulfato de cálcio) é utilizada no caso de formações contendo esse tipo de sal. A gilsonita é usada em poço que atravessa camada de folhelho. A gilsonita cobre a superfície do folhelho evitando que este absorva água e se expanda, obstruindo o poço.

Atualmente, tem-se dado preferência aos polímeros sintéticos ou outros produtos químicos como polifosfatos, lignitos, taninos e sais de potássio. Para a prevenção dos problemas citados, pode-se também optar por um fluido à base de óleo. $\mathrm{O}$ uso desse tipo de fluido, no entanto, sofre restriçôes devido aos problemas ambientais causados.

\section{e) Lubrificantes}

$\mathrm{O}$ atrito provocado pelo contato do metal com a rocha resulta em desgaste e aquecimento da broca. O fluido proporciona o resfriamento e pode conter um insumo mineral (geralmente, grafita ou bentonita) com a função de lubrificante. Em situaçóes especiais a preferência é por produtos à base de glicol. 


\section{2 - Produção}

A região Nordeste brasileiro tem se destacado ao longo dos anos como importante fornecedora de insumos minerais usados na perfuração de poços de petróleo. Em 2010, a produção de bentonita bruta no Brasil duplicou em relação ao ano anterior. A regiáo contribuiu com aproximadamente $95 \%$ da produção nacional. A produção regional foi obtida nos estados da Paraíba e Bahia. Do total produzido, 79,3\% foram destinados à extração de petróleo e gás (SILVA, 2011) que também consumiu 3,5\% da bentonita ativada produzida naquele ano.

Em 2010, a produção de barita manteve-se estável quando comparada com o ano anterior. A região nordeste, que até o ano de 2007 era a principal produtora, foi superada pela região centro-oeste. A produção nordestina de barita bruta, toda oriunda do Estado da Bahia, representou apenas 16\% do total. A região, no entanto, continua sendo a maior produtora da barita beneficiada com 56\% do total nacional (ARAÚJO, 2011). A extraçáo de petróleo consumiu $11,5 \%$ da produção bruta e $8 \%$ da barita beneficiada.

\section{3 - Caracterização tecnológica}

\section{1 - Bentonita}

As bentonitas da região nordeste são cálcicas e estão localizadas nos municípios de Boa Vista, Pedra Lavada e Cubatí no Estado da Paraíba e no município de Vitória da Conquista, na Bahia. A lavra é feita a céu aberto, sendo bastante prejudicada no período de chuvas (LUZ \& OLIVEIRA, 2008). Na Paraíba são conhecidos diferentes tipos de bentonita que diferem na coloração sendo, localmente, denominados como: verde-lodo, chocolate, choco-bofe e bofe. A bentonita verde lodo apresenta o maior potencial para uso em lamas de perfuração (BALTAR et al., 2003).

A Tabela 1 apresenta a composição química da argila verde-lodo, enquanto a Tabela 2 apresenta as fases cristalinas observadas em análise por difração de raios-X. Na Tabela 3 são apresentados alguns resultados de um estudo de caracterização realizado com a bentonita verde-lodo (BALTAR et al., 2003).

Tabela 1 - Composição química da bentonita do tipo verde-lodo.

\begin{tabular}{lllllllllll}
\hline $\mathrm{Al}_{2} \mathrm{O}_{3}$ & $\mathrm{CaO}$ & $\mathrm{Fe}_{2} \mathrm{O}_{3}$ & $\mathrm{~K}_{2} \mathrm{O}$ & $\mathrm{MgO}$ & $\mathrm{MnO}$ & $\mathrm{Na}_{2} \mathrm{O}$ & $\mathrm{P}_{2} \mathrm{O}_{5}$ & $\mathrm{SiO}_{2}$ & $\mathrm{TiO}_{2}$ & P.F. \\
\hline 20,5 & 0,43 & 9,2 & 1,30 & 2,3 & 0,04 & 0,45 & 0,05 & 53,6 & 1,20 & 10,03 \\
\hline
\end{tabular}

Tabela 2 - Fases cristalinas observadas em análise por DRX na bentonita verde-lodo

\begin{tabular}{cccc}
\hline ESMECTITA & QUARTZO & CAULINITA & MICROCLÍNIO \\
\hline presente & presente & presente & vestígios \\
\hline
\end{tabular}

Fonte: Baltar et al. (2003-a) 
Tabela 3 - Características tecnológicas apresentadas pela bentonita verde-lodo.

\begin{tabular}{cc}
\hline CARACTERÍSTICA & RESULTADO \\
\hline Capacidade de troca catiônica $(\mathrm{meq} / 100 \mathrm{~g})$ & 54 \\
Viscosidade plástica $(\mathrm{cP})$ & 2,5 \\
Grau de inchamento livre $(\%)$ & 6,0 \\
Expansáo $(\%)$ & 40,0 \\
Menor do que $74 \mu \mathrm{m}(\%)$ & 98,2 \\
Área superficial externa $(\mathrm{m} 2 / \mathrm{g})$ & 87,0 \\
Ponto isoelétrico & $\mathrm{pH}=2,9$ \\
\hline
\end{tabular}

Fonte: Baltar et al. (2003-a)

A bentonita verde-lodo também se mostrou propícia para a modificação superficial (BALTAR et al., 2010). Após contato com um sal quaternário de amônia (brometo dodeciltrimetil de amônia - BDTA) apresentou aumento de viscosidade (Figura 1), modificação da carga elétrica superficial (Figura 2) e hidrofobicidade (Figura 3).

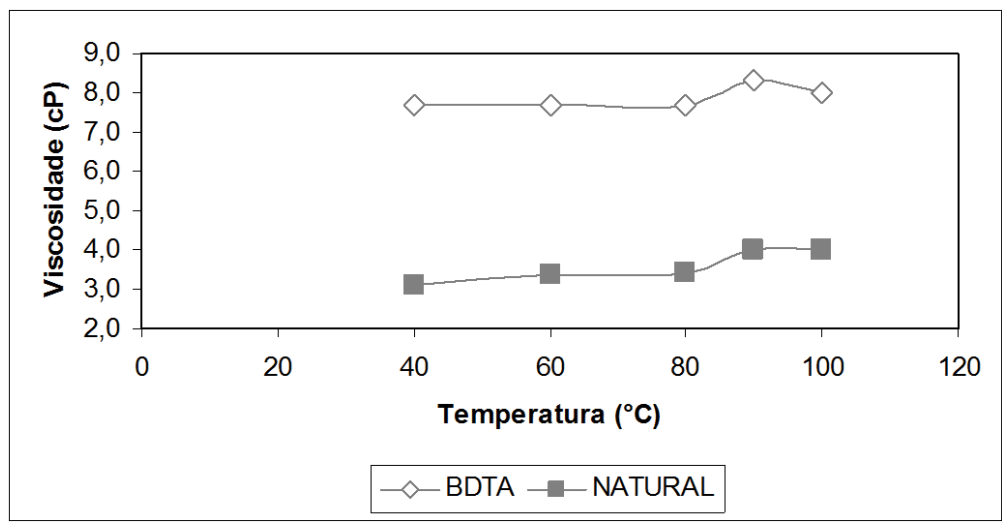

Figura 1 - Influência da variação da temperatura de aquecimento da amostra na viscosidade da suspensão em querosene para a bentonita nas formas natural e modificada (BALTAR et al., 2010).

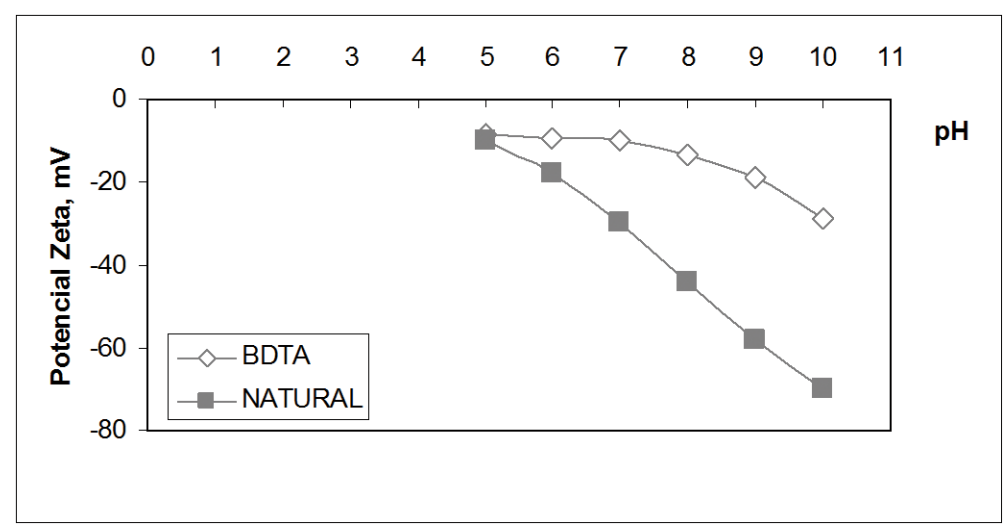

Figura 2 - Influência da modificação superficial da bentonita no potencial zeta em função do pH. 


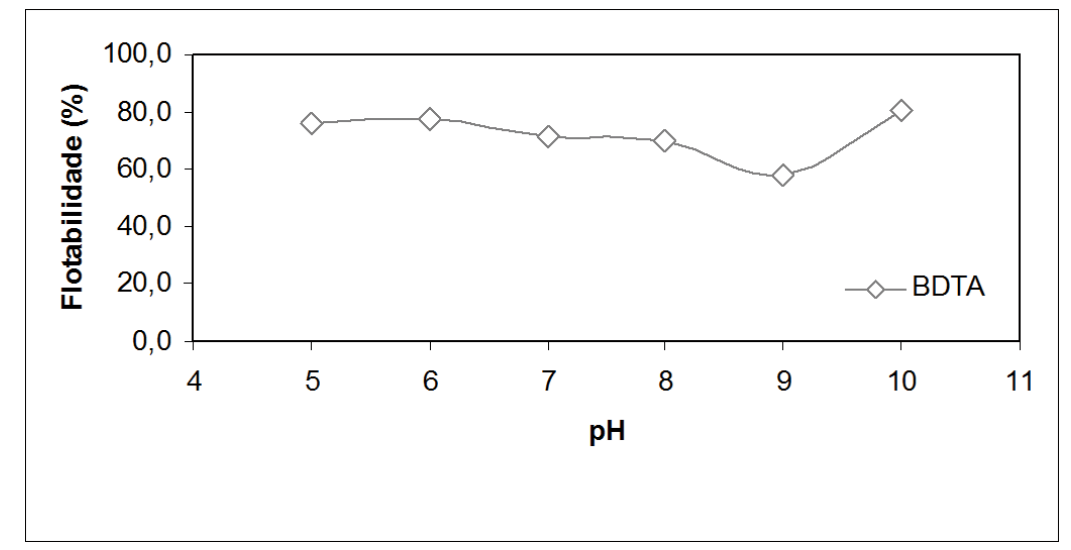

319

Figura 3 - Flotabilidade da bentonita modificada com BDTA em pH 9 em funçáo do pH do sistema durante a flotação.

\section{2 - Barita}

$\mathrm{Na}$ regiāo nordeste, a barita ocorre em doze municípios do Estado da Bahia sendo a de maior importância econômica a do município de Miguel Calmon (Luz \& Baltar, 2008). Uma amostra representativa do pátio de estocagem da empresa produtora foi caracterizada por Baltar et al. (2003-b). A composição química é apresentada na Tabela 4.

Tabela 4 - Composição química da amostra de barita.

\begin{tabular}{llllllllll}
\hline COMPOSTO & $\mathrm{BaSO} 4$ & $\mathrm{SrO}$ & $\mathrm{Al} 2 \mathrm{O} 3$ & $\mathrm{Fe} 2 \mathrm{O} 3$ & $\mathrm{CaO}$ & $\mathrm{K} 2 \mathrm{O}$ & $\mathrm{MgO}$ & $\mathrm{SiO} 2$ & P.F. \\
\hline TEOR (\%) & 86,6 & 0,67 & 0,36 & 0,40 & 0,04 & 0,04 & $<0,1$ & 11,4 & zero \\
\hline
\end{tabular}

Fonte: Baltar et al. (2003-b)

P.F. - perda ao fogo

Os resultados mostram um minério rica em barita com o quartzo aparecendo como o principal contaminante. A ausência de perda ao fogo sugere a ausência de carbonatos e minerais hidratados (anfibólios, micas, caolinitas). Esse fato é importante porque facilita bastante o processo de flotação no beneficiamento do minério.

Tabela 5 - Composição mineralógica do minério de barita de Miguel Calmon

\begin{tabular}{ccccc}
\hline MINERAL & BARITA & QUARTZO & HIALOFÂNIO & $\begin{array}{c}\text { ÓXIDOS E } \\
\text { HIDRÓXIDOS } \\
\text { DE FERRO }\end{array}$ \\
\hline TEOR $(\%)$ & 87,3 & 10,6 & 1,6 & 0,4 \\
\hline
\end{tabular}




\section{4 - Conclusóes}

A formulação de uma "lama" é de fundamental importância para o êxito da perfura-

ção de poços de petróleo. A região nordeste do Brasil participa com destaque na produção desses insumos minerais, especialmente, bentonita e barita.

Em 2010, a regiâo nordeste contribuiu com aproximadamente $95 \%$ da produção nacional de bentonita pura e $16 \%$ da barita bruta. A produçâo regional foi obtida nos estados da Paraíba e Bahia.

A amostra de bentonita denominada verde-lodo apresenta o maior potencial para uso em lamas de perfuração de poços de petróleo. Enquanto a barita de Miguel Calmon, na Bahia, apresenta um elevado teor em sulfato de bário e uma contaminação à base de quartzo o que facilita bastante o beneficiamento por flotação.

\section{Referências Bibliográficas}

ARAÚJO, R. M. (2011) - Barita. Sumário Mineral Brasileiro 2011. Departamento Nacional da Produçáo Mineral - DNPM.

BALTAR, C. A. M.; LUZ, A. B.; OLIVEIRA, C. H. \& ARANHA, I. B. (2003-a) - Caracterização, Ativação e Modificação Superficial de Bentonitas Brasileiras. In.: Baltar, C.A.M. e Luz, A.B. (editores). Insumos Minerais para a Perfuração de Poços de Petróleo. Capítulo 2, p. 21-46.

BALTAR, C. A. M.; LUZ, A. B. \& NEUMANN, R. (2003-b) - Caracterização e Beneficiamento da Barita de Miguel Calmon-BA. In.: Baltar, C. A. M. e Luz, A. B. (editores). Insumos Minerais para a Perfuração de Poços de Petróleo. Capítulo 3, p. 47-61.

BAlTAR, C. A. M.; SAMPAIO, J. A. \& OliveirA, G. A. R. (2010). Estudo das Condições para a Modificação Superficial de uma Bentonita. In.: II Simpósio de Minerais Industriais do Nordeste. Campina Grande (Paraíba), p. 39-46.

DARLEY, H. C.; GRAY, G. R. (1988). Composition and Properties of Drilling and Completation Fluids. Fifth Edition. Gulf Publishing Company, 634 p.

LUZ, A. B. \& BALTAR, C. A. M. (2003) - A Funçáo dos Minerais Industriais Componentes da Lama de Perfuração de Poços. In.: Baltar, C. A. M. e Luz, A. B. (editores). Insumos Minerais para a Perfuração de Poços de Petróleo. Capítulo 1, p. 11-20.

LUZ, A. B. \& BALTAR, C. A. M. (2008) - Barita. In.: Luz, A.B. e Lins, F.A.F. (editores). Rochas \& Minerais Industriais. CETEM/MCT, Capítulo 13, CETEM-MCT, 295-310.

LUZ, A. B. \& OLIVEIRA, C. H. (2008) - Argila Bentonita. In.: Luz, A. B. e Lins, F. A. F. (editores). Rochas \& Minerais Industriais. CETEM/MCT, Capítulo 11, CETEM-MCT, 239-253.

SILVA, T. H. C. (2011) - Bentonita. Sumário Mineral Brasileiro 2011. Departamento Nacional da Produção Mineral - DNPM. 